\title{
AKTIVITAS GEL EKSTRAK RIMPANG KUNYIT (Curcuma domestica Val) TERHADAP BAKTERI Staphylococcus aureus
}

\author{
Afidatul Muadifah ${ }^{1}$, Amalia Eka Putri ${ }^{2}$, Nur Latifah ${ }^{3}$ \\ ${ }^{1,2,3}$ Program Studi Farmasi, Sekolah Tinggi Ilmu Kesehatan Karya Putra Bangsa Tulungagung, Jalan Raya \\ Tulungagung-Blitar KM 4, Sumbergempol,Tulungagung \\ Email : afyda31@gmail.com
}

\begin{abstract}
Indonesia is a country that has various medicinal herbs. One type of medicinal plant that is often used for trea Indonesia is a country that has various medicinal herbs. One type of medicinal plant that is often used for treatment is the turmeric rhizome. Turmeric rhizome contains alkaloid compounds, tannins and flavonoids. This research was conducted in vitro to investigate the activity both of turmeric extract and gel from turmeric extract against $S$. aureus using disk diffusion method. The extraction turmeric from turmeric rhizome was performed by soxhlet method using $96 \%$ ethanol as solvent. We varied the concentration of turmeric extract such as $45 \%, 55 \%, 65 \%$ and $75 \%$. The optimum concentration which has high bacterrial activity was applied in gel formulation. The results of this study indicate that turmeric extract $45 \%$ exhibited strong antibacterial activity against $S$.aureus with inhibition zone diameter of $11 \mathrm{~mm}$. Other concentrations of $55 \%, 65 \%$ and $75 \%$ gave inhibition zone diameter of $10,10,5$ and 10,1 respectively. Gel was formulated using $45 \%$ turmeric extract. The gel generated antibacterial activity of $19 \mathrm{~mm}$ in inhibition zone diameter. Evaluation of gel showed a good result such as organoleptic, homogeneity, $\mathrm{pH}$, spreading capacity test in accordance with the standard of gel preparation. However, the adhesion and gel stability test are not favorable in relative to the standard gel preparation.
\end{abstract}

keywords: turmeric extract, soxhlet method, gel, Staphylococcus aureus

\section{PENDAHULUAN}

Indonesia merupakan negara yang memiliki keanekaragaman hayati yang sangat melimpah. Hal ini yang mendorong daya tarik masyarakat untuk menggunakan tanaman berkhasiat obat untuk pengobatan secara tradisional. Para ahli terus melakukan pengembangan dengan pengujian dan penelitian dari berbagai tanaman yang berkhasiat obat agar dapat dikembangkan dalam suatu pengobatan pada penyakit tertentu. Pengalaman dan pengetahuan masyarakat mengenai semua penggunaan tanaman obat telah dikumpulkan untuk dijadikan dasar dari pengembangan penelitian menggunakan tanaman berkhasiat obat.

Salah satu tanaman berkhasiat obat yang sering digunakan masyarakat untuk pengobatan tradisional adalah kunyit (Curcuma domestica Val) terutama pada bagian rimpangnya. Masyarakat Indonesia sering menggunakan rimpang kunyit sebagai obat antiradang, antidiare, obat masuk angin, mengobati gatal, luka dan sesak nafas (Maulidya \& Sari, 2016). Aktivitas farmakologi rimpang kunyit lainnya yaitu sebagai antiinflamasi, anti imunodefisiensi, antivirus, antibakteri, antijamur, antioksidan, antikarsinogenik dan anti 
Jurnal SainHealth Vol. 3 No. Edisi Maret 2019

(C) Fakultas Ilmu Kesehatan Universitas Maarif Hasyim Latif Sidoarjo

p-ISSN : 2548-8333

e-ISSN : $2549-2586$

infeksi (Rajesh H. dkk, 2013).

Kunyit (Curcuma domestica Val) memiliki berbagai kandungan senyawa seperti alkaloid, flavonoid, kurkumin, minyak atsiri, saponin, tanin dan terpenoid. Kurkumin dan minyak atsiri telah terbukti memiliki kemampuan sebagai antiinflamasi. Selain itu, golongan senyawa kurkuminoid memiliki kandungan yang berkhasiat sebagai antibakteri, antikejang, analgetik, antidiare, antipiretik dan antitumor. Senyawa kurkumin sama seperti dengan senyawa kimia lain seperti antibiotik, alkaloid, steroid, minyak atsiri, resin, dan fenol yang termasuk ke dalam hasil metabolit sekunder dari suatu tanaman (Kristina dkk, 2007; Wijayakusuma H, 2008; dan Indrayanto 1987).

Pemanfaatan senyawa pada rimpang kunyit sebagai antibakteri telah diteliti dan dilakukan pengujian oleh Pangemanan dkk, 2016 yang menunjukkan bahwa ekstrak etanol rimpang kunyit dengan metode maserasi menggunakan pelarut etanol 95\% memiliki aktivitas antibakteri terhadap pertumbuhan bakteri Staphylococcus aureus dan Pseudomonas sp.

Metode pengujian aktivitas antibakteri yang akan digunakan dalam penelitian ini adalah metode pengujian antibakteri secara difusi in vitro untuk mengetahui potensi ekstrak rimpang kunyit sebagai pengobatan antibakteri pada kulit. Kultur bakteri yang digunakan sebagai pengujian adalah bakteri Staphylococcus aureus. Penggunaan perbedaan konsentrasi, kontrol positif dan kontrol negatif digunakan untuk mengetahui penyebaran luas terhadap diameter pertumbuhan bakteri Staphylococcus aureus.

Ekstrak rimpang kunyit yang memiliki aktivitas antibakteri, selanjutnya akan dikembangkan lebih lanjut dalam bentuk sediaan topikal untuk mempermudah penggunaannya sebagai antibakteri. Gel merupakan sistem semipadat yang terdiri dari suspensi yang dibuat dari partikel anorganik yang kecil atau molekul organik yang besar dan terpenetrasi ke dalam duatu cairan (Departemen Kesehatan RI, 1995). Pemilihan sediaan gel ini didasarkan pada pernyataan menurut Ansel, 2005 bahwa sediaan gel mampu memberikan rasa dingin di kulit sehingga menimbulkan rasa nyaman pada saat diaplikasikan di daerah yang dituju dan sediaannya mudah mengering membentuk lapisan film yang mudah dicuci dengan air.

Berdasarkan penjelasan uraian di atas, maka penulis akan melakukan penelitian tentang aktivitas gel ekstrak rimpang kunyit (Curcuma domestica $\mathrm{Val}$ ) terhadap pertumbuhan bakteri Staphylococcus aureus.

\section{METODE PENELITIAN}

\section{Alat dan Bahan}

Alat yang digunakan dalam penelitian ini adalah pisau, blender, ayakan dengan no mesh 60, timbangan digital miligram, serangkaian alat sokhletasi, tabung reaksi, cawan petri, kawat ose, pipet ukur, pipet tetes, spiritus, gelas ukur, batang pengaduk, erlemeyer, objek glass, mikroskop, oven, kertas cakram / blank disk, mortir dan stamper, SPSS 16.

Bahan yang digunakan dalam penelitian ini adalah bakteri Staphylococcus aureus ATCC 25923, Nutrient Agar, Nutrient Broth, indikator $\mathrm{pH}$, kapas, aluminium foil, kertas saring, aquadestilata, etanol $96 \%$, etanol $70 \%$, oil mercy, gentian violet, iodine, safranin, parafin cair, fenolftalein, $\mathrm{KOH} 0,1 \%$.

Pengambilan sampel dilakukan di desa Campurdarat Kabupaten Tulungagung Jawa Timur. Sampel yang diambil adalah rimpang kunyit yang telah berusia 8 bulan keatas dengan ciri fisik tanamannya telah mengering pada bagian daunnya dan memiliki ukuran rimpang sekitar $5-7 \mathrm{~cm}$ serta berwarna orange. 
Jurnal SainHealth Vol. 3 No. Edisi Maret 2019

(C) Fakultas Ilmu Kesehatan Universitas Maarif Hasyim Latif Sidoarjo

p-ISSN : 2548-8333

e-ISSN : 2549-2586

\section{Prosedur Penelitian}

\section{Determinasi Tanaman}

Determinasi tanaman rimpang kunyit dilakukan untuk memastikan bahwa simplisia yang dipakai sesuai dengan jenis dan spesiesnya.

\section{Ekstraksi Rimpang Kunyit}

Simplisia rimpang kunyit sebanyak $3 \mathrm{~kg}$ diproses melalui proses penyortiran, perajangan dan pengeringan. Rimpang kunyit dikeringkan dengan cara dikering-anginkan selama 5 hari kemudian dihaluskan dan diayak serbuk dengan mesh no. 60. Serbuk ditimbang sebanyak sebanyak 40 gram yang selanjutnya dilakukan proses ekstraksi sokhlet dengan pelarut etanol 96\% sebanyak $400 \mathrm{~mL}$. Hasil proses ekstraksi mendapatkan ekstrak cair sebanyak $350 \mathrm{~mL}$ kemudian dikeringkan menggunakan oven selama 7 hari untuk didapatkan ekstrak kering 7 gram. Ekstrak yang didapatkan dibuat variasi konsentrasi 45\%, 55\%, 65\% dan 75\%.

\section{Uji Bebas Etanol}

Uji bebas etanol dilakukan dengan cara menimbang 1 gram ekstrak kering lalu ditambahkan $\mathrm{H}_{2} \mathrm{SO}_{4}(\mathrm{p})$ dan $\quad \mathrm{CH}_{3} \mathrm{COOH}$ kemudian dipanaskan di atas bunsen. Jika hasil pemanasan, ekstrak masih tercium bau ester maka ekstrak masih mengandung etanol (Kurniawati, 2015).

\section{Uji Kadar Air}

Uji kadar air dilakukan dengan cara menimbang serbuk rimpang kunyit sebanyak 10 gram yang kemudian dimasukkan dalam oven dengan suhu $105^{\circ} \mathrm{C}$ selama 5 jam. Hasil pemanasan ditimbang dan dilakukan pengulangan sampai didapatkan hasil yang konstan (Depkes RI, 2000).

\section{Uji Aktivitas Ekstrak}

Pengujian aktivitas antibakteri ekstrak rimpang kunyit dilakukan dengan menggunakan metode difusi (disk diffusion). Suspensi bakteri Staphylococcus aureus yang telah dibuat dengan kekeruhan yang sama dengan Mc. Farland, digoreskan pada media nutrient agar (NA) dengan bantuan cotton buds steril agar dapat meminimalisir media agar tidak sobek saat proses penggoresan. Blank disk steril yang digunakan memiliki diameter sebesar $6 \mathrm{~mm}$, dan pemberian ekstrak ke dalam blank disk yaitu sebesar $10 \mu \mathrm{L}$. Selanjutnya dilakukan penempelan blank disk dengan menggunakan pinset steril untuk dengan memberi sedikit tekanan untuk memastikan bahwa telah terjadi kontak antara blank disk dan media. Kontrol negatif (DMSO 5\%), kontrol positif (gel clindamycin), dan dari ekstrak rimpang kunyit konsentrasi I (45\%), konsentrasi II (55\%), konsentrasi III (65\%) dan konsentrasi IV (75\%). Selesai penempelan blank disk pada media, plate dibungkus kertas atau koran dan ditali dengan kuat lalu segera diinkubasi di inkubator pada suhu $37^{\circ} \mathrm{C}$ dengan lama waktu $18-24$ jam. Kadar hambat minimum (KHM) ditandai dengan timbulnya daerah zona bening (Ismiati \& Tri lestari, 2014).

Pengamatan dilakukan setelah 24 jam masa inkubasi. Daerah bening yang ditimbulkan merupakan petunjuk kepekaan bakteri terhadap antibiotik atau bahan antibakteri lainnya yang digunakan sebagai bahan uji yang dinyatakan dengan luas jangkauan diameter zona hambat. Diameter zona hambat dihitung dalam satuan millimeter ( $\mathrm{mm}$ ) menggunakan jangka sorong atau penggaris. Kemudian diameter zona hambat tersebut dikategorikan sebagai kekuatan daya antibakterinya.

\section{Formulasi Sediaan Gel}

Tabel 1. Formula Standart diadaptasi dari Aprana et al. (2016)

\begin{tabular}{cc}
\hline Bahan & Konsentrasi \\
\hline Maserat daun & $0,1 \%$ \\
Karbopol & $0,1 \%$ \\
Propilen glikol & $2 \%$ \\
Etanol & $0,1 \%$ \\
EDTA & $0,003 \%$ \\
Metil paraben & $0,01 \%$
\end{tabular}


Jurnal SainHealth Vol. 3 No. Edisi Maret 2019

(C) Fakultas Ilmu Kesehatan Universitas Maarif Hasyim Latif Sidoarjo

p-ISSN : 2548-8333

e-ISSN : 2549-2586

Propil paraben

$0,01 \%$

Aqua destilata

ad $100 \mathrm{ml}$

TEA

q.s

Tabel 2. Formulasi Gel Ekstrak Rimpang Kunyit

\begin{tabular}{cc}
\hline Bahan & Konsentrasi \\
\hline ekstrak rimpang & Konsentrasi optimum \\
Karbopol & $0,1 \%$ \\
Propilen glikol & $2 \%$ \\
Etanol & $0,1 \%$ \\
EDTA & $0,003 \%$ \\
Metil paraben & $0,01 \%$ \\
Propil paraben & $0,01 \%$ \\
Aqua destilata & ad $20 \mathrm{ml}$ \\
TEA & q.s \\
\hline
\end{tabular}

\section{Pembuatan Gel}

Formula yang digunakan dalam pembuatan gel ekstrak rimpang kunyit dapat dilihat diatas. Disiapkan semua bahan yang akan digunakan. Ditimbang karbopol sebanyak 0,1 g dan ditaburkan diatas $20 \mathrm{ml}$ aquadestilata panas yang diletakkan di dalam mortir lalu didiamkan selama 24 jam sampai mengembang sehingga terbentuk massa gel. Dibagi volume aquadestilata menjadi dua bagian. Bagian pertama terdiri dari ekstrak rimpang kunyit dan propilen glikol dalam 9,75 $\mathrm{ml}$ aquadestilata. Bagian kedua terdiri dari metil paraben dan propil paraben dalam 9,75 $\mathrm{ml}$ aquadestilata. Karbopol yang sudah mengembang sempurna kemudian diaduk sampai homogen dengan kecepatan yang konstan agar tidak menimbulkan adanya gelembung udara. Tahap selanjutnya yaitu memasukkan kedua bagian zat yang telah dilarutkan dalam beaker glass dan ditambahkan TEA tetes demi tetes sambil diaduk untuk membentuk konsistensi gel kemudian sediaan gel yang dibuat siap untuk dilakukan evaluasi gel (Aprana et al., 2016).

Pembuatan gel menggunakan konsentrasi ekstrak sebesar $0,1 \%$ dari ekstrak $45 \%$ yang diambil dengan cara di mikropipet. Pembuatan gel dimulai dari konsentrasi terkecil terlebih dahulu, jika dengan konsentrasi ekstrak $0,1 \%$ tidak mampu memberikan hambatan maka harus ditingkatkan lagi konsentrasi ekstraknya menjadi $0,5 \%$ sampai didapatkan konsentrasi minimum yang dapat memberikan daya hambat antibakteri yang maksimum. Semakin tinggi konsentrasi ekstrak yang dimasukkan dalam sediaan akan memengaruhi warna sediaan yang dibuat, misalnya ekstrak rimpang kunyit yang memiliki sifat warna kuning yang sangat kuat akan memengaruhi hasil akhir dari warna sediaan. Semakin banyak ekstrak yang dimasukkan dalam basis gel maka warna kuning yang akan dihasilkan sediaan akan semakin pekat karena dalam ekstrak rimpang kunyit senyawa kurkumin sebagai pembawa warna kuning alami akan tetap memengaruhi tingkat kekeruhannya. Ekstrak kunyit yang memiliki daya hambat minimum berada pada konsentrasi $45 \%$, sehingga konsentrasi yang dilanjutkan ke proses pembuatan sediaan memakai konsentrasi ekstrak rimpang kunyit 45\%.

\section{Evaluasi Sediaan Gel}

\section{Uji Organoleptik}

Pemeriksaan organoleptik gel ekstrak etanol rimpang kunyit dilakukan dengan menilai perubahan bentuk, warna dan bau (Ditjen POM, 2000).

\section{Uji Homogenitas}

Pengujian homogenitas sediaan dilakukan dengan cara mengoleskan sediaan pada sekeping kaca atau bahan transparan lain yang cocok, sediaan harus menunjukkan susunan yang homogen dan tidak terlihat adanya butir-butir yang kasar (Dirjen POM, 1979).

Sediaan yang memiliki homogenitas yang baik ditandai dengan tidak terdapatnya 
Jurnal SainHealth Vol. 3 No. Edisi Maret 2019

(C) Fakultas Ilmu Kesehatan Universitas Maarif Hasyim Latif Sidoarjo

p-ISSN : 2548-8333

e-ISSN : $2549-2586$

gumpalan pada hasil pengolesan, struktur yang rata dan memiliki warna yang seragam dari titik awal pengolesan sampai titik akhir pengolesan. Sediaan yang diuji sebaiknya diambil dari tiga tempat dalam wadah yaitu bagian atas, tengah dan bawah dari wadah.

\section{Uji Daya Lekat}

Uji daya lekat dilakukan dengan cara meletakkan sediaan secukupnya diantara kedua kaca objek. Kemudian diberi beban $1 \mathrm{~kg}$ selama 5 menit. Kedua objek tersebut dipisahkan dengan menarik kaca objek yang di atas dengan beban seberat $80 \mathrm{~g}$ melewati sebuah kontrol, sedangkan kaca objek yang dibawah ditahan dengan beban. Lamanya waktu yang diperlukan untuk memisahkan kedua objek tersebut dicatat sebagai waktu daya lekat.

Uji Daya Sebar

Pengujian daya sebar dilakukan dengan cara menimbang sediaan dan meletakkan $0,5 \mathrm{~g}$ sediaan di antara dua lempeng objek transparan yang diberi beban $150 \mathrm{~g}$. Pengukuran diameter daya sebar dilakukan setelah sediaan tidak dapat menyebar kembali atau lebih kurang 1 menit setelah pemberian beban. Diameter daya sebar sediaan yang baik antara 5-7 cm (Garg A, et al., 2002).

Uji pH

Pengukuran nilai $\mathrm{pH}$ menggunakan alat bantu stik $\mathrm{pH}$ universal yang dicelupkan kedalam $0,5 \mathrm{~g}$ sediaan yang telah diencerkan dengan $5 \mathrm{~mL}$ aquadest. Nilai $\mathrm{pH}$ sediaan yang baik adalah 4,5-6,5 atau sesuai dengan nilai $\mathrm{pH}$ kulit manusia (Tranggono, 2007).

\section{Uji Proteksi}

Uji Proteksi dilakukan dengan cara mengambil sepotong kertas saring yang dibasahi dengan larutan fenolftalein untuk indikator secara merata pada permukaan kertas saring, setelah itu keringkan. Olesi kertas dengan gel. Sementara itu pada kertas saring yang lain (2) bagian tepinya diolesi dengan parafin padat yang dilelehkan. Setelah kering/dingin akan didapat areal yang dibatasi dengan parafin. Tempel kertas saring (2) pada kertas saring (1) Teteskan/basahi areal dengan larutan $\mathrm{KOH} \mathrm{0,1}$ N. Dilihat apakah kertas saring menunjukan noda berwarna merah/kemerahan (waktu 15, 30, 45, 60 detik, 3 menit dan 5 menit). Kalau tidak ada noda berarti gel dapat memberikan proteksi terhadap cairan (larutan $\mathrm{KOH}$ ).

Uji Stabilitas

Uji kestabilan sediaan meliputi warna, bau, homogenitas, dan $\mathrm{pH}$ dievaluasi pada suhu rendah $\left(4 \pm 2^{\circ} \mathrm{C}\right)$, suhu kamar $\left(27 \pm 2^{\circ} \mathrm{C}\right)$ dan suhu tinggi $\left(40 \pm 2^{\circ} \mathrm{C}\right)$ (Sugiyati et al., 2015).Uji stabilitas yang dilakukan selama 4 minggu, bahwa semua formula menunjukkan homogenitas yang baik.

\section{Uji Aktivitas Antibakteri Sediaan Gel Ekstrak}

\section{Rimpang Kunyit}

Uji aktivitas antibakteri sediaan gel ekstrak rimpang kunyit dilakukan dengan cara yang sama dengan uji aktivitas antibakteri ekstrak rimpang kunyit namun hanya menggunakan konsentrasi ekstrak yang maksimum dalam penghambatan pertumbuhan bakteri Staphylococcus aureus.

\section{Analisa Hasil}

Data hasil penelitian aktivitas antibakteri ekstrak rimpang kunyit terhadap penghambatan bakteri Staphylococcus aureus dianalisis menggunakan program SPSS 16 untuk melihat apakah ekstrak rimpang kunyit mampu menghambat pertumbuhan bakteri Staphylococcus aureus secara signifikan atau tidak. Pengolahan data dapat dilakukan setelah penentuan uji normalitas. Uji normalitas adalah uji untuk mengukur apakah data mempunyai distribusi yang normal atau tidak, sehingga data distribusi yang normal dapat digunakan dalam statistik parametrik dan jika data tidak terdistribusi normal, dapat digunakan dalam statistik non parametrik. Uji normalitas dilakukan dengan Kolmogorov-Smirnov. Data 
terdistribusi normal jika memiliki Sig $>0,05$ dan jika Sig $<0,05$ maka data tidak terdistribusi normal (Sujarweni, 2012).

Data yang terdistribusi normal, selanjutnya dianalisis dengan One-Way Anova. Data diterima jika Sig $>0,05$ dan jika Sig $<0,05$ maka data ditolak (Yamin dan Kurniawan, 2014). Asumsi One-Way Anova dilakukan dengan uji homogenitas yang bertujuan untuk menguji kesamaan (homogenitas) beberapa sampel, yakni seragam tidaknya variasi sampelsampel yang diambil dari populasi yang sama (Ghazali, 2011). Pengujian homogenitas dilakukan dengan menggunakan levene statistics. $\mathrm{H} 0$ ditolak jika $\mathrm{p}$ value levene statistics $<0,05$ (Yamin dan Kurniawan, 2014). Data yang tidak terdistribusi normal, selanjutnya akan dianalisis dengan uji Kruskall Wallis.

\section{HASIL DAN PEMBAHASAN}

\section{Determinasi Tanaman}

Hasil dari determinasi menyatakan bahwa simplisia yang digunakan adalah adalah rimpang kunyit dengan spesies Curcuma domestica Val.

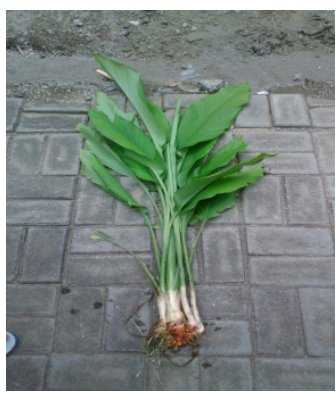

Gambar 1. Tanaman kunyit dari daerah Campurdarat Kab Tulungagung

\section{Ekstraksi Rimpang Kunyit}

Hasil pengeringan 1,5 kg (rimpang kunyit basah) didapatkan rimpang kunyit sebanyak 1,3 $\mathrm{kg}$ dan didapatkan serbuk halus rimpang kunyit sebanyak 443,99 gram. Hasil proses sokhletasi (menggunakan 8 sirkulasi) didapatkan rendemen maserat sebanyak $34,16 \%$. Hasil rendemen ini lebih tinggi dibandingkan dengan hasil rendemen ekstrak yang diperoleh dari hasil penelitian Pricilia dan Saptarini (2016) yang menyatakan bahwa rendemen sohklet yang didapatkan $12,66 \%$. Perbedaan hasil rendemen bisa dipengaruhi oleh tempat pananaman, tingkat ketinggian, dan waktu pemanenan.

\section{Uji Kadar Air}

Pengujian kadar air dilakukan untuk mengetahui kandungan air dan mengurangi kemungkinan simplisia terkontaminasi bakteri dan sebagaimana pada Tabel 1, didapatkan hasil kadar air sebesar 5,8\%.

Tabel 3. Hasil Uji Kadar Air

\begin{tabular}{cccc}
\hline Sampel & $\begin{array}{c}\text { Berat awal } \\
(\mathrm{g})\end{array}$ & $\begin{array}{c}\text { Setelah di } \\
\text { oven }(\mathrm{g})\end{array}$ & $\begin{array}{c}\text { Kadar Air } \\
(\%)\end{array}$ \\
Serbuk simplisia & 10 & 31,40 & 5,8 \\
\hline
\end{tabular}

\section{Uji Bebas Etanol}

Ekstrak kering rimpang kunyit selanjutnya dilakukan uji bebas bebas etanol dengan menambahkan $\mathrm{H}_{2} \mathrm{SO}_{4}$ dan $\mathrm{CH}_{3} \mathrm{COOH}$. Hasil uji bebas etanol yaitu ekstrak kering rimpang kunyit tidak mengandung etanol karena tidak memberikan bau ester setelah dilakukan pemanasan. Uji bebas etanol dilakukan untuk memastikan bahwa ekstrak rimpang kunyit yang akan di uji aktivitas antibakteri telah terbebas dari etanol.

\section{Uji Aktivitas Ekstrak Rimpang Kunyit}

Ekstrak yang diperoleh di uji aktivitas antibakteri dengan menggunakan variasi konsentrasi 45\%, 55\%, 65\% dan 75\% dengan menggunakan kontrol positif gel clyndamycin, kontrol negatif DMSO 5\%. Pelarut yang digunakan untuk melarutkan ekstrak yaitu DMSO 5\% karena DMSO dapat melarutkan senyawa polar dan non polar dan pelarut ini tidak menimbulkan efek antibakteri pada konsentrasi di bawah $10 \%$.

Pengujian variasi konsentrasi ini digunakan 
Jurnal SainHealth Vol. 3 No. Edisi Maret 2019

(C) Fakultas Ilmu Kesehatan Universitas Maarif Hasyim Latif Sidoarjo

p-ISSN : 2548-8333

e-ISSN : 2549-2586

untuk mengetahui konsentrasi minimum yang dapat memberikan zona hambat yang optimum terhadap pertumbuhan bakteri Staphylococcus aureus. Metode yang digunakan yaitu metode difusi agar dengan kertas cakram. Suspensi bakteri s.aureus digoreskan pada media agar menggunakan kawat ose secara merata dengan 4 arah penggoresan. Setelah media ditanami dengan bakteri, kertas cakram ditanamkan pada media dan diberi ekstrak rimpang kunyit sebanyak $10 \mu \mathrm{L}$ lalu diinkubasi pada suhu $37^{\circ} \mathrm{C}$ selama 24 jam dan diamati hasil diameter zona hambat yang ditimbulkan.

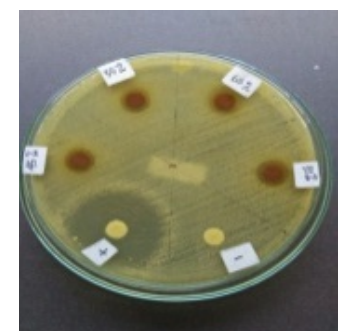

Gambar 2. Uji aktivitas ekstrak rimpang kunyit

Tabel 4. Hasil Uji Aktivitas Antibakteri Ekstrak

\begin{tabular}{cc}
\multicolumn{2}{c}{ Rimpang Kunyit } \\
\hline Sampel & $\begin{array}{c}\text { Diameter Zona Hambat } \\
(\mathrm{mm}) \pm \mathrm{SD}\end{array}$ \\
\hline ERK 45\% & $11 \pm 1,25$ \\
ERK 55\% & $10 \pm 0,50$ \\
ERK 65\% & $10,5 \pm 0,50$ \\
ERK 75 \% & $10,1 \pm 0,76$ \\
Kontrol (+) & 27,6 \\
Kontrol (-) & 0 \\
\hline & \\
Keterangan : ERK yaitu Estrak Rimpang Kunyit, \\
Kontrol (+) yaitu gel clyndamicin, Kontrol (-) \\
yaitu DMSO 5\%
\end{tabular}

Hasil uji aktivitas antibakteri yang memberikan aktivitas antibakteri yang optimum diberikan oleh konsentrasi 45\% dengan diameter zona hambat sebesar $12,5 \mathrm{~mm}$ sebagaimana dalam Gambar 2 dan Tabel 4. Respon diameter zona hambat yang ditimbulkan termasuk dalam kategori respon pertumbuhan bakteri yang kuat (Pratama, 2005).

Analisis Hasil Uji Aktivitas Antibakteri Ekstrak Rimpang Kunyit

Tabel 5. Analisis Hasil Uji Aktivitas Antibakteri Ekstrak Rimpang Kunyit

\begin{tabular}{ccc}
\hline Analisa Data & Metode Uji & Sig. \\
\hline Uji Normalitas & $\begin{array}{c}\text { Kolmogorov- } \\
\text { Smirnov Test }\end{array}$ & 0,897 \\
Uji & $\begin{array}{c}\text { Levene Statistic } \\
\text { Homogenitas }\end{array}$ & 0,530 \\
Analisa Hasil & $\begin{array}{l}\text { One-Way } \\
\text { ANOVA }\end{array}$ & 0,296 \\
\hline
\end{tabular}

Berdasarkan Tabel 5. Hasil dari analisa data yang dilakukan menggunakan SPSS 16 didapatkan hasil yang homogen pada ekstrak kunyit. Uji normalitas dilakukan dengan Kolmogorov-Smirnov. Data berdistribusi normal jika Sig $>0,05$ dan jika Sig $<0,05$ maka data tidak berdistribusi normal (Sujarweni, 2012).

Data yang terdistribusi normal, selanjutnya dianalisis dengan One-Way Anova. Data diterima jika Sig $>0,05$ dan jika Sig $<0,05$ maka data ditolak (Yamin dan Kurniawan, 2014). Asumsi One-Way Anova dilakukan dengan uji homogenitas yang bertujuan untuk menguji kesamaan (homogenitas) beberapa sampel, yakni seragam tidaknya variasi sampelsampel yang diambil dari populasi yang sama (Ghazali, 2011). Pengujian homogenitas dilakukan dengan menggunakan levene statistics.

Uji variasi ekstrak kunyit menunjukkan uji normalitas dengan Kolmogorov-Smirnov menghasilkan Sig sebesar 0,897 yang artinya data memiliki distribusi yang normal untuk dilanjutkan pada uji Homogenity of variences, 
Jurnal SainHealth Vol. 3 No. Edisi Maret 2019

(C) Fakultas Ilmu Kesehatan Universitas Maarif Hasyim Latif Sidoarjo

p-ISSN : 2548-8333

e-ISSN : 2549-2586

hasil yang pada uji ini Homogenity of variences didapatkan Sig sebesar 0,530 yang berarti data memiliki homogenitas yang baik dan didapatkan hasil uji ANOVA sebesar 0,296.

\section{Evaluasi Gel}

Tabel 6. Hasil Evaluasi Gel Ekstrak Rimpang Kunyit

\begin{tabular}{ccc}
\hline Evaluasi Gel & Hasil & Standart \\
\hline Organoleptis & & \\
a. Bentuk & Semi padat & Semi padat \\
b. Warna & Kuning & Transparan \\
& transparan & \\
c. Bau & Tidak & - \\
& berbau & \\
Homogenitas & Homogen & Homogen \\
pH & $7 \pm 0,00$ & $4,5-6,5$ \\
Daya Sebar & $5,75 \pm 0,86$ & $5-7 \mathrm{~cm}$ \\
Daya Lekat & $0,71 \pm 0,16$ & $>1$ detik \\
Daya Proteksi & Tidak & Tidak \\
& berwarna & Berwarna \\
\hline
\end{tabular}

Pada Tabel 5 diperoleh hasil evaluasi gel ekstrak rimpang kunyit, yaitu berdasarkan dari organoleptis sediaan gel yang terbentuk sudah sesuai dengan standar, demikian juga untuk nilai homogenitas, $\mathrm{pH}$ (sesuai $\mathrm{pH}$ kulit), daya sebar dan daya proteksi. Hasil evaluasi daya lekat kurang sesuai dengan standart uji daya lekat sediaan semisolid yang menyatakan bahwa uji daya lekat yang baik adalah lebih dari 1 detik dan kurang dari 4 detik.

\section{Uji Aktivitas Antibakteri Gel Ekstrak Rimpang Kunyit}

Diameter zona hambat yang ditimbulkan dari kontrol positif lebih besar dibandingkan dengan uji sediaan gel ekstrak $45 \%$, diameter zona hambatanya sangat kuat yakni berada diatas rentang $20 \mathrm{~mm}$. Kontrol negatif yang tidak memiliki diameter zona hambat dikarenakan aquadestilata merupakan media pertumbuhan yang baik untuk bakteri, sehingga aquadestilata tidak menimbulkan efek antibakteri terhadap bakteri Staphylococcus aureus. Hasil uji aktivitas antibakteri sediaan gel ekstrak rimpang kunyit memiliki sedikit selisih jika dibandingkan dengan kontrol positif, ratarata dari sediaan gel ekstrak rimpang kunyit memiliki diameter zona hambat sebesar 19 mm sedangkan hasil kontrol positif gel clyndamicin memiliki diameter zona hambat sebesar 27,6 mm sebagaimana tercantum pada Tabel 7. Perbedaan ini membuktikan bahwa sediaan gel ekstrak rimpang kunyit memiliki aktivitas antibakteri yang kuat untuk penghambatan terhadap pertumbuhan bakteri Staphylococcus aureus.

Tabel 7. Hasil Uji Aktivitas Antibakteri Gel Ekstrak Rimpang Kunyit

\begin{tabular}{|c|c|}
\hline Sampel & $\begin{array}{l}\text { Diameter Zona } \\
\text { Hambat }(\mathrm{mm}) \pm \\
\text { SD }\end{array}$ \\
\hline $\begin{array}{l}\text { Gel Ekstrak Rimpang } \\
\text { Kunyit } 45 \%\end{array}$ & $19 \pm 3,75$ \\
\hline Kontrol positif & $27,5 \pm 2,17$ \\
\hline Kontrol negatif & $0,00 \pm 0,00$ \\
\hline $\begin{array}{l}\text { Keterangan : Kontrol }(+) \text { y } \\
\text { Kontrol (-) yaitu aquadesti }\end{array}$ & $\begin{array}{l}\text { vaitu gel clyndamicin } \\
\text { ilata }\end{array}$ \\
\hline \multicolumn{2}{|c|}{$\begin{array}{l}\text { KESIMPULAN DAN SARAN } \\
\text { Kesimpulan }\end{array}$} \\
\hline $\begin{array}{l}\text { 1. Ekstrak rimpang } \\
\text { domestica Val) } \\
\text { antibakteri terhadap ba } \\
\text { aureus. }\end{array}$ & $\begin{array}{cr}\text { kunyit } & \text { (Curcuma } \\
\text { memiliki } & \text { aktivitas } \\
\text { akteri Staphylococcus }\end{array}$ \\
\hline $\begin{array}{l}\text { 2. Variasi konsentrasi ek } \\
\text { yang memiliki zon } \\
\text { terbesar terdapat pac } \\
\text { dengan diameter zona }\end{array}$ & $\begin{array}{l}\text { kstrak rimpang kunyit } \\
\text { ha hambat rata-rata } \\
\text { ida konsentrasi } 45 \%\end{array}$ \\
\hline
\end{tabular}


Jurnal SainHealth Vol. 3 No. Edisi Maret 2019

(C) Fakultas Ilmu Kesehatan Universitas Maarif Hasyim Latif Sidoarjo

p-ISSN : 2548-8333

e-ISSN : $2549-2586$

mm yang termasuk dalam respon hambatan yang kuat.

3. Sediaan gel ekstrak rimpang kunyit $45 \%$ memiliki diameter zona hambat sebesar 19 $\mathrm{mm}$ (kategori kuat dalam menghambat pertumbuhan bakteri Staphylococcus aureus).

\section{Saran}

Perlu dilakukan penelitian lebih lanjut tentang efek farmakologis sediaan gel ekstrak rimpang kunyit

\section{DAFTAR PUSTAKA}

Aprana N. G. 2016. Formulation and evaluation of anti-microbial herbal gel of curcumin and nyctanthes abor tritis leaves extract. World Journal of Pharmacy and Pharmaceutical Sciences, Vol. 5, No. 6, 1718-1729.

Departemen Kesehatan Republik Indonesia.1995. Farmakope Indonesia IV,. Penerbit Dirjen POM : Jakarta.

Departemen Kesehatan Republik Indonesia. 2000. Parameter Standart Umum Ekstrak

Tanaman Obat. Cetakan 1. Jakarta

Ditjen POM. 2000. Materia Medika Indonesia. Jilid vimateria medika indonesia.Jilid VI. Jakarta: Departemen Kesehatan RI.

Ditjen POM. 2000. Parameter Standar Umum Ekstrak Tumbuhan Obat. Jakarta: Depkes RI.

Garg. 2002. Spreading of semisolid formulation: An Update. Pharmaceutical Tecnology. 84-102.

Indrayanto, G. 1987. Produksi Metabolit Sekunder dengan Teknik Kultur Jaringan Tanaman. Seminar Nasional Metabolit Sekunder. PAU Bioteknologi- Universitas Gajah Mada. pp. 4-6
Ismiati, N. d. 2014. Pengembangan formulasi masker ekstrak air daun alpukat (Persea americana mill) sebagai antibakteri Staphylococcus aureus untuk pengobatan jerawat. Pharmaçiana, Vol. 4, No. 1, 45-52.

Kristina N.N, Noveriza R, Syahid R.S, Rizal M, 2007. "Peluang Peningkatan Kadar Kurkumin pada Tanaman Kunyit dan Temulawak". Balai Penelitian Tanaman Obat dan Aromatik. http://balito.litbang.deptan.go.id//edisikhusus/ 2007_01/edisikhusus2007_01_01.pdf hal 1,25.

Kurniawati. 2015. Keragaman dan kelimpahan musuh alami hama pada habitat padi yang dimanipulasi dengan tumbuhan berbunga. Ilmu Pertanian 18 (1): 31-36.

Maulidya S, Sari A. 2016. Formulasi Sediaan Salep Ekstrak Etanol Rimpang Kunyit (Curcuma longa Linn) SEL Vol. 3No. 1 Juli 2016: 16-23

Pangemanan, A., Fatimawali., Budiarso. F. 2016. Uji daya hambat ekstrak rimpang kunyit (Curcuma longa) terhadap pertumbuhan bakteri Staphylococcus aureus dan Pseudomonas sp.Jurnal eBiomedik (eBM).Volume 4, Nomor 1.

Pratama, M. R. 2005. Pengaruh Ekstrak Serbuk Kayu Siwak (Salvadora persica) Terhadap Pertumbuhan Bakteri Streptococcus mutans dan staphylococcus aureus dengan metode difusi agar. Bogor: skripsi.IPB.

Rajesh H. et al., 2013. Phytochemical Analysis Of Methanolic Extract Of Curcuma Longa Linn Rhizome, International Journal Of Universal Pharmacy And Bio Sciences, ISSN 2319-8141

Sujarweni, V. W. 2012. SPSS untuk Paramedis. Yogyakarta: Gava Medika. 
Jurnal SainHealth Vol. 3 No. Edisi Maret 2019

C Fakultas Ilmu Kesehatan Universitas Maarif Hasyim Latif Sidoarjo

p-ISSN : 2548-8333

e-ISSN : 2549-2586

Tranggono, R. D. 2007. Buku Pegangan

Ilmu Pengetahuan Kosmetik Editor:

Joshita Djajadisastra. Jakarta:

Penerbit Pustaka Utama.

Wijayakusuma, H.M.H., et ., al. 1992. Tanaman

Berkhasiat Obat di Indonesia. Jakarta:

Pustaka Kartini 